\title{
Incorporating FOAM into medical student and resident education
}

\section{Karalynn Otterness}

Department of Emergency Medicine, Stony Brook University Hospital, Stony Brook, NY, USA

Gone are the days of solely utilizing textbooks and lectures to teach medical students and residents. Although core content textbooks remain important to teach the fundamentals, free open access medical education (FOAM) can greatly enhance traditional teaching models by exposing learners to cutting edge concepts through a dynamic collection of visual and auditory resources which encourage collaboration, information sharing and knowledge translation. ${ }^{1}$ To understand how to best teach today's technologically inclined students and residents, one must understand some fundamental aspects of adult millennial learners. Born into a digital world, millennials have known technology their entire lives. Millennials crave variety, prefer a more informal teaching environment, and are comfortable multi-tasking. ${ }^{2}$ FOAM fits this bill, as a multitude of podcasts, blogs and videocasts exists, spanning a wide range of focus areas (critical care, toxicology, ultrasound, etc.). Millennials are more likely to learn when the concepts being taught are directly relevant to their real lives or chosen careers. This concept lends itself well to FOAM, as FOAMspecific search engines exist (i.e., http://FOAMsearch.net) which allow users to choose topics relevant to their learning preferences. A resident can quickly access FOAM videos to refresh his or her knowledge prior to performing a procedure in the emergency department; you cannot get more directly relevant to real life than that. Most importantly, residents themselves feel that FOAM is worthwhile to their education. A study by Mallin et al. ${ }^{3}$ of approximately 400 emergency medicine residents revealed that $70.3 \%$ felt podcasts were the most beneficial to their education, compared to $54.3 \%$ who felt that textbooks were most beneficial.

We now recognize the potential that FOAM offers, but how can we successfully incorporate FOAM into our medical school and residency curricula? The easiest and least time consuming technique could involve distributing a list of residency-approved FOAM websites and then allowing residents to explore and learn at their own leisure. The same could be done for medical students, with a focus on resources which teach basic, fundamental concepts such as Steve Carroll's EM Basic podcast (http://embasic.org). There are several blogs and articles about how to get started using FOAM which should be relayed to students and new interns; R.E.B.E.L. EM's "Got FOAM" post (http://rebelem.com/got-foam/) is a good example.

Another technique is to create a social media account for the residency program, such as a Twitter account. This allows FOAM resources to be shared with any learner following that account, and provides the opportunity to interact with the social media community in real time to pose questions that arise during weekly conference or to prompt further discussion. In 2014 there were at least sixty residency programs in the US and Canada that had twitter accounts. ${ }^{4}$ Going one step further, a residency program can create its own FOAM site to post resident and faculty created blogs, podcasts, and videocasts, which is a great way to get residents actively involved in their own education.
Received: 25 November 2016 Revised: 27 January 2017

Accepted: 31 January 2017

Correspondence to: Karalynn Otterness Department of Emergency Medicine, Stony Brook University Hospital, Health Sciences Center Level 4-Room 080, Stony Brook, NY 11794, USA E-mail:karalynn.otterness@ stonybrookmedicine.edu

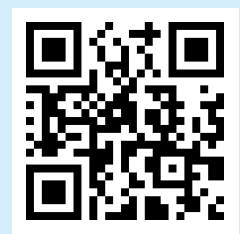

How to cite this article: Otterness K. Incorporating FOAM into medical student and resident education. Clin Exp Emerg Med 2017;4(2):119-120.

This is an Open Access article distributed under the terms of the Creative Commons Attribution Non-Commercial License (http:// creativecommons.org/licenses/by-nc/4.0/). 
FOAM can also be utilized as part of a flipped classroom approach to resident conference activities. In this model, residents are given online materials to review prior to in-person didactics, which are then used to clarify, solidify and/or demonstrate the newly acquired knowledge. ${ }^{5}$ By completing some independent study prior to conference, the didactics can be focused and highyield since everyone should theoretically show up with a similar level of understanding, thus allowing for complex, higher level learning to occur in-person. More time can be devoted to active learning exercises and discussion if the basics were already covered prior to the group didactic activity. In one single center study, 36 out of 38 residents surveyed preferred a flipped classroom format to a traditional lecture. ${ }^{6}$ In another study, 98\% (48/49) of medical staff preferred the flipped classroom approach. ${ }^{7}$

Lastly, FOAM can supplement resident education as part of an asynchronous learning curriculum. Asynchronous learning is a student-centered educational model in which online resources are used to enable information sharing between learners connected via a network. ${ }^{8}$ Staffing an emergency department around the clock challenges the ability to congregate all residents simultaneously for learning purposes. Not limited by place or time, asynchronous learning allows a portion of the academic work to take place outside of the classroom, in a web-based virtual learning environment. A quiz or other method of ensuring comprehension accompanies each learning activity. Successful implementation of asynchronous learning modules has been achieved in emergency medicine. ${ }^{9}$

Founded over a pint of Guinness in Dublin, ${ }^{10}$ FOAM has evolved to become an essential learning tool for modern day emergency medicine students and residents. FOAM allows individuals to widely distribute and share content and ideas in a collective learning environment. There are several opportunities to incorporate FOAM into a medical curriculum, so get creative. Cheers!

\section{CONFLICT OF INTEREST}

No potential conflict of interest relevant to this article was reported.

\section{REFERENCES}

1. Nickson $C P$, Cadogan MD. Free open access medical education (FOAM) for the emergency physician. Emerg Med Australas 2014;26:76-83.

2. Novotney A. Engaging the millennial learner: new research suggests that variety may be the best way to engage today's undergraduates [Internet]. Washington, DC: American Psycholog-ical Association; 2010 [cited 2016 Jul 15]. Available from: http://www.apa.org/monitor/2010/03/undergraduates. aspx.

3. Mallin M, Schlein S, Doctor S, Stroud S, Dawson M, Fix M. A survey of the current utilization of asynchronous education among emergency medicine residents in the United States. Acad Med 2014;89:598-601.

4. Scott KR, Hsu CH, Johnson NJ, Mamtani M, Conlon LW, DeRoos FJ. Integration of social media in emergency medicine residency curriculum. Ann Emerg Med 2014;64:396-404.

5. McLaughlin JE, Roth MT, Glatt DM, et al. The flipped classroom: a course redesign to foster learning and engagement in a health professions school. Acad Med 2014;89:236-43.

6. Young TP, Bailey CJ, Guptill M, Thorp AW, Thomas TL. The flipped classroom: a modality for mixed asynchronous and synchronous learning in a residency program. West J Emerg Med 2014;15:938-44.

7. Tan E, Brainard A, Larkin GL. Acceptability of the flipped classroom approach for in-house teaching in emergency medicine. Emerg Med Australas 2015;27:453-9.

8. Techopedia. Asynchronous learning [Internet]. [place unknown]: Techopedia [cited 2016 Jul 15]. Available from: https://www.techopedia.com/definition/23154/asynchronous-learning.

9. Ashton A, Bhati R. The use of an asynchronous learning network for senior house officers in emergency medicine. Emerg Med J 2007;24:427-8.

10. Shaw G. Breaking news: don't call it social media: FOAM and the future of medical educa-tion. Emerg Med News 2013;35: 1-30. 